\title{
LETTER
}

\section{Clostridium difficile outcomes difficult to generalize}

\author{
Naresh Nagella*, Khenj-Jim Lim and Amay Parikh \\ See related research by Zahar et al., http://ccforum.com/content/16/6/R215
}

We read with interest the previous issue of Critical Care, in which Zahar and colleagues [1] described Clostridium difficile infection (CDI) in patients during an intensive care unit (ICU) stay. Given some limitations of the authors' study, it is difficult to generalize from the results that CDI detected early will not affect ICU length of stay or mortality.

The carrier effect, in which up to $20 \%$ of hospitalized patients can be chronic carriers of $C$. difficile, can affect results [2]. Unfortunately, chronic carriers are not identified. Furthermore, the 72-hour cutoff for ICU-acquired C. difficile seems somewhat arbitrary as it can be acquired faster and some patients were admitted to the ICU within the first 72 hours of hospital exposure [3]. In addition, variance in the first-line treatment of acquired CDI and its effect on treatment outcomes is unreported.
Also, the detection immunoassay used a sensitivity well below (80\%) those of the widely available cytotoxin neutralization assay (96\%) and toxigenic culture (100\%) [4]. Next, it is unclear whether the two populations were equally sick. The (younger) patients with diarrheal C. difficile were mechanically ventilated longer and received more proton pump inhibitors. Accordingly, unreported severity descriptors such as leukocytosis or renal insufficiency could influence mortality outcomes. Furthermore, total hospital length of stay should be compared since $C$. difficile diarrhea alone does not necessitate admission to the ICU. The retrospective cohort trial is appropriate, but testing stronger strains of C. difficile, using higher-sensitivity detection methods, and tracking the entire length of stay would more accurately support the authors' conclusions.

\section{Authors' response}

Jean-Ralph Zahar and Jean-François Timsit

We thank Nagella and colleagues for their kind comments about our study [1] and would like to address some of the issues they raise. As they pointed out, up to $20 \%$ of hospitalized patients can be chronic carriers. However, we wish to emphasize that, to avoid this bias, we restricted our study to patients with a new ICU-acquired CDI. We selected patients with CDI acquired after 72 hours as the exposed population. We agree that this arbitrary cut-point may have slightly decreased the incidence of ICU-acquired CDI. As stated by Zar and colleagues [5], vancomycin is the treatment of choice for severe CDIs. As described in our paper, most patients received metronidazole as first-line treatment, although

*Correspondence: nagellna@umdnj.edu

Pulmonary and Critical Care Division, Department of Medicine, Robert Wood Johnson Medical School, 1 Robert Wood Johnson Place, P.O. Box 19, New Brunswick, NJ 08903-0019, USA most of them had severe CDI. This approach could have affected the mortality rate of patients with ICU-acquired CDI. However, the effects of CDI on mortality were strictly similar in subgroups receiving metronidazole or vancomycin as first-line treatments. Owing to the $80 \%$ sensitivity of the test, some patients with CDI may have been falsely considered unexposed, leading to an artificial decrease in the over-risk of death associated with CDI. However, we checked all of the stools received by the lab during the same hospitalization, and no patients who were CDI-negative became CDI-positive during the same hospital stay. Furthermore, as stated in the paper, a secondary analysis, excluding patients who received metronidazole or vancomycin within 48 hours following a negative test, gave similar results. Finally, many factors may influence mortality and length of stay in the ICU [6]. We used modern statistical methods to take into account all measured time-fixed and time-dependent characteristics that may have acted as confounders. Of course, we cannot ensure that other unmeasured confounders did not exist, as they may exist in all cohort studies. 


\section{Abbreviations}

CDI, Clostridium difficile infection; ICU, intensive care unit.

\section{Competing interests}

The authors declare that they have no competing interests.

Published: 22 February 2013

\section{References}

1. Zahar JR, Schwebel C, Adrie C, Garrouste-Orgeas M, Français A, Vesin A, Nguile-Makao M, Tabah A, Laupland K, Le-Monnier A, Timsit JF; the OUTCOMEREA study group: Outcome of ICU patients with Clostridium difficile infection. Crit Care 2012, 16:R215.

2. Barbut F, Mastrantonio P, Delmée M, Brazier J, Kuijper E, Poxton I; European Study Group on Clostridium difficile (ESGCD): Prospective study of Clostridium difficile infections in Europe with phenotypic and genotypic characterisation of the isolates. Clin Microbiol Infect 2007, 13:1048-1057.

3. Katz DA, Lynch ME, Littenberg B: Clinical prediction rules to optimize cytotoxin testing for Clostridium difficile in hospitalized patients with diarrhea. Am J Med 1996, 100:487-495.
4. Buchan BW, Mackey TL, Daly JA, Alger G, Denys GA, Peterson LR, Kehl SC, Ledeboer NA: Multicenter clinical evaluation of the portrait toxigenic C. difficile assay for detection of toxigenic Clostridium difficile strains in clinical stool specimens. J Clin Microbiol 2012, 50:3932-3936.

5. Zar FA, Bakkanagari SR, Moorthi KM, Davis MB: A comparison of vancomycin and metronidazole for the treatment of Clostridium difficile-associated diarrhea, stratified by disease severity. Clin Infect Dis 2007, 45:302-307.

6. Garrouste Orgeas M, Timsit JF, Soufir L, Tafflet M, Adrie C, Philippart F, Zahar JR, Clec'h C, Goldran-Toledano D, Jamali S, Dumenil AS, Azoulay E, Carlet J; Outcomerea Study Group: Impact of adverse events on outcomes in intensive care unit patients. Crit Care Med 2008, 36:2041-2047.

doi:10.1186/cc11935

Cite this article as: Nagealla N, et al:: Clostridium difficile outcomes difficult to generalize. Critical Care 2013, 17:415. 